$5,26 \%$, dịch tồn dư 3 trường hợp chiếm 3,16\% và áp xe 1 trường hợp chiếm 1,05\%. Các trường hợp này đều đáp ứng với điều trị nội khoa, không có trường hợp nào phải can thiệp ngoại khoa. Tỷ lệ biến chứng của chúng tôi cũng tương tự như tác giả: G. Frongia 10,4\% trường hợp với những biến chứng thường gặp là áp xe, tắc ruột và nhiễm trùng [7]. Theo tác giả Y. Yousef thì có $9,8 \%$ trường hợp áp xe thường gặp khi ruột thừa võ tạo thành 1 hay nhiều ổ áp xe và $4,9 \%$ bị nhiễm trùng sau mổ.

Phẫu thuật của chúng tôi thành công $100 \%$ trong đó có $90,53 \%$ kết quả tốt, 9,47\% kết quả trung bình và $0 \%$ kết quả xấu. Không có trường nào chuyển mổ mở. Chúng tôi thây rằng kết quả phẫu thuật của chúng tôi cũng tương tự như các tác giả trong và ngoài nước [1],[2], [7]

\section{KẾT LUẬN}

Qua 95 bệnh nhân VPMRT ở trẻ em được điều trị bằng PTNS tại bệnh viện Nhi Trung Ương chúng tôi thấy rằng: đây là phương pháp an toàn không có biến chứng nặng với tỷ lệ thành công $100 \%$ cho kết quả tốt $90,53 \%$, trung bình 9,47\% và không có kết quả xấu.

\section{TÀl LIẸU THAM KHẢO}

1. Cảnh, Phan Xuân (2015), " Đánh giá kết quả phẩu thuật nôi soi điêu trị viêm phúc mac ruột thừa ở tré em", Bệnh viện Đa khoa tỉnh Bình Định.

2. Đại, Trân Quãng và Lình, Trưỡng Nguyễn Uy (2016), "'Đánh giá kết quả phấu thuật nội soi điều trị viêm ruôt thừa có biến chứng ở trẻ em"'", Y Hoc TP. Hồ Chí Minh. 20(1), tr. 180-184.

3. Lẳm, Pham Lê Huy, Uyên, Nguyễn Thị Bích và Linh, Trương Nguyễn Uy (2019), "Kết quả điều tri viêm phúc mac ruôt thứa không dấn lưu ở trẻ em bằng kỹ thuật nội soi", Y Học TP. Hồ Chí Minh. 23(1), tr. 174-179.

4. Lê Huy Thạch, Lê Văn Thanh, Đỗ Thùy Dung, Ngô Văn Thhắng (2021), "Đặc điểm để kháng kháng sinh của các vi khuân gây bệnh thường gặp tại bệnh viện đa khoa tỉnh ninh thuận năm 2020", Y Học TP. Hî̀ Chí Minh. 25(1), tr. 178-185.

5. Nguyễn Thị Hồng Vân, Trân Ngọc Sơn, Phạm Đức Hiệp (2021), "Điếu trị viêm phúc mạc ruột thừa ở tree em bằng phấu thuât nội soi môt trocar không đặt dẫn lưu ", Tạp Chí Ý Học Việt Nam 498 (1), tr. 170-174.

6. Chang, H. K. et al. (2013), "Feasibility of a laparoscopic approach for generalized peritonitis from perforated appendicitis in children", Yonsei Med J. 54(6), tr. 1478-83.

7. Frongia, G. et al. (2016), "Predicting Postoperative Complications After Pediatric Perforated Appendicitis", J Invest Surg. 29(4), pp. 185-94.

8. Ikeda, Hitoshi et al. (2004), "Laparoscopic versus open appendectomy in children with uncomplicated and complicated appendicitis", Journal of Pediatric Surgery. 39(11), pp. 1680-1685.

9. Schmidt, Yannick Michael et al. (2020), "Prophylactic Drain Placement in Childhood Perforated Appendicitis: Does Spillage Matter?", Frontiers in Pediatrics. 8.

10. Wang, X. et al. (2009),"Complicated appendicitis in children: is laparoscopic appendectomy appropriate? A comparative study with the open appendectomy--our experience", J Pediatr Surg. 44(10), pp. 1924-7.

\title{
ĐÁNH GIÁ KẾT QUẢ ĐIỀU TRI LẤY TUỶ BUỒNG RĂNG HÀM SŨ̃A Ở TRẺ 4-8 TUỔI VỚI MTA VÀ BIODENTINE
}

\section{Lê Thị Thuỳ Linh*, Lê Minh Giang*, Nguyễn Thị Thu Phương*}

\section{TÓM TẮT}

Bênh lý tuỷ răng sữa là một trong những bênh phổ biến ở trẻ em. Để điêuu trị bệnh lý này đã có nhiêu phương pháp được sử dụng và lây tuỷ buồng là một trong những kỹ thuật được dùng phổ biến cho trẻ. Hiệu quả của phương pháp này phụ thuộc vào nhiều yếu tố, đặc biệt là vật liệu đăt trong tủy buồng. Vì vậy, muc đích của nghiên cứu này nhằm đánh giá kết quả điểu tri lấy tủy buồng răng hàm sữa ở trẻ 4-8 tuổi bằng Biodentine so với nhóm chứng sử dụng MTA. Nghiên cứu can thiệp lâm sàng có đối chứng tiến hành

*Viện Đào tạo Răng Hàm Mặt, Trướng Đại học Y Hà Nội Chiu trách nhiêm chính: Lê Thi Thuỳ Linh

Email: lethuylinh@hmu.edu.vn

Ngày nhận bài: 20.9.2021

Ngày phản biên khoa họ: 15.11.2021

Ngày duyệt bài: 23.11.2021 trên 77 trẻ từ 4-8 tuổi với 192 hàm sữa phù hợp vỡ́i chỉ định lấy tuỷ buồng được chia thành 2 nhóm. Mỗi nhóm có 96 răng trong đó nhóm I sử dụng MTA đặt trong buồng tuỷ và nhóm II là Biodentine. Sau 9 tháng theo dõi tỷ lệ thành công trên lâm sàng và Xquang của nhóm İ là $98,7 \%$ và $96,1 \%$; nhóm II tương ứng là 98,8\% và 97,6\%; sự khác biệt giữa hai nhóm không có ý nghĩa thống kê với $p>0,05$. Tữ đó có thể kết luận: Biodentine và MTA có tỷ lệ thành công tương tự nhau trong điều trị lấy tuỷ buồng răng hàm sữa ở trẻ sau 9 tháng điều trị. Tuy nhiên cần có thời gian theo dõi dài hơn để đánh giá chính xác hiệu quả của vât liêuu này.

Tử khoá: răng hàm sữa, lấy tuỷ buông, Biodentine, MTA.

\section{SUMMARY}

EVALUATION OF THE TREATMENT OUTCOME OF PULPOTOMY IN PRIMARY 


\section{MOLARS OF CHILDREN AGED 4-8 YEARS WITH MTA AND BIODENTINE}

Pulp pathology in deciduous teeth is one of the most common diseases in children. In order to treat this one, a number of methods has been used and pulpotomy is one of the most popular techniques. The effectiveness of this method depends on some factors, especially the material placed in the pulp chamber. Therefore, the aim of this study was to compare the effectiveness of Biodentine to MTA used as pulpotomy agents in primary molars of children 4-8 years old. This was a randomized controlled trial study. A total of 192 primary molar teeth which had indication for pulpotomy in 77 patients aged from 4 to 8 years were assessed in the study. Random assignment of the pulpotomy medicaments was done as follows: Group I, MTA $(n=96)$; Group II, Biodentine $(n=96)$. The clinical and radiographic success rates were $98,7 \%$; $96,1 \%$ of group I and $98,8 \% ; 97,6 \%$ of group II after 9 months follow-up, respectively. They were not different statistically $(p>0,05)$. Pulpotomy treatment using Biodentine and MTA had similar success rates in primary molar teeth at the end of the 9 month followup period. The clinical trials with longer follow-up periods are required to accurately evaluate the effectiveness of this material.

Key words: Primary molar teeth, Pulpotomy, Biodentine, MTA

\section{I. ĐĂT VẤN ĐỀ}

Theo hướng dẫn của Viện hàn lâm Răng trẻ em Hoa Kỳ (AAPD) trường hợp lộ tủy khi lấy sạch ngà mềm, ngà mủn hoặc lộ tủy do cơ học thì điều trị lấy tủy buồng là một chỉ định phù hợp [1] nhằm duy trì sự sống của tủy chân, bảo tồn sự toàn vẹn của răng. Hiệu quả của phương pháp này phụ thuộc vào mức độ tổn thương của tủy, kỹ thuật điêu trị tủy và vật liệu đặt trong tủy buồng. Từ lâu đã có nhiều vật liệu được sử dụng trong điều trị lấy tuỷ buồng như Formocresol $(F C)$, Glutaraldehyde, Laser...tuy nhiên, Mineral trioxide aggregate (MTA) được biết đến là vật liệu có tỷ lệ thành công rất cao (trên $90 \%$ ) và ít gầy hại tế bào [2]. Nhưng MTA vẫn có nhược điểm là khó thao tác, khả năng đông cứng lâu (2 tiếng 45 phút) và làm đổi màu răng [3]. Để cải thiện nhược điểm này, Biodentine (với thành phẩn chính của bột là tricalcium silicate và nước trộn là calcium chloride) đã ra đời nhằm rút ngắn thời gian đông cứng (9-12 phút) của vật liệu điều này rất phù hợp với việc điều trị trên bệnh nhân là trẻ nhỏ [4].

ở nước ta đã có một số công trình nghiên cứu đánh giá hiệu quả điều trị tuỷ buồng của một số vật liệu nhưng chưa có nhiều nghiên cứu được tiến hành để so sánh hiệu quả của Biodentine và MTA. Vì vậy, chúng tôi thực hiện đề tài với mục tiêu "Đánh giá hiệu quả điều trị lấy tủy buồng răng hàm sữa ở trẻ 4-8 tuổi bằng Biodentine so với nhóm chứng sử dụng MTA".

II. ĐỐl TƯỢNG VÀ PHƯƠNG PHÁP NGHIÊN CỨU

2.1. Đối tượng nghiên cứu. Là các răng hàm sữa sâu có chỉ định điều trị tuỷ buồng.

*Tiêu chuẩn lựa chọn. Răng hàm sữa sâu có chỉ định điều trị tủy buồng ở bệnh nhân từ 48 tuổi với các biểu hiện trên lâm sàng và Xquang như sau:

- Trên lâm sàng: Răng có lỗ sâu, đáy lỗ sâu cách trần buồng tủy một lớp ngà mềm, ngà mủn hoăcc có điểm hở tuỷ. Bệnh nhân chưa từng có tiền sử đau tự nhiên, răng không lung lay, vùng lợi quanh răng bình thường, không nề đỏ, ấn không đau, không có lỗ dò, sẹo dò, áp xe.

- Trên Xquang: Lỗ sâu cách trần buồng tuỷ một lớp ngà mỏng dưới $1,5 \mathrm{~mm}$. Vùng dây chằng nha chu và xương ổ răng bình thường.

- Răng có khả năng phục hồi lại thân răng.

- Sau khi lấy toàn bộ tủy buồng, tủy chân răng phải cầm máu được bằng bông vô khuẩn sau 5 phút.

- Bệnh nhân và cha mẹ đồng ý tham gia nghiên cứu.

*Tiêu chuẩn loại trừ

- Răng sắp thay.

- Trên Xquang có hình ảnh nội tiêu, ngoại tiêu, tiêu xương vùng chẽ chân răng.

- Bệnh nhân có các bệnh tim mạnh (hẹp hở van 2 lá, suy tim), viêm cầu thận, rối loạn đông máu... hoăc các bênh toàn thân chưa điêu trị ổn định.

\subsection{Phương pháp nghiên cứu}

2.2.1. Thiết kế nghiên cứu: nghiên cứu can thiệp lâm sàng ngẫu nhiên có đối chứng

\subsection{2. Địa điểm và thời gian nghiên cứu}

- Đia điểm nghiên cứu: Trung tâm kỹ thuât cao nhà A7 - Viện Đào tạo Răng Hàm Mặt Trường Đại học Y Hà Nội và khoa Răng hàm mặt - Bệnh viện Nhi Trung ương

- Thời gian nghiên cứu: Từ tháng 04/2018 đến tháng 09/2021

\subsubsection{Cõ̃ mẫu}

$\mathrm{n}_{1}=\mathrm{n}_{2}=$

$$
\frac{\left[Z_{\left(1-\frac{\alpha}{2}\right)} \sqrt{2 p(1-p)}+Z_{(1-\beta)} \sqrt{p 1(1-p 1)+p 2(1-p 2)}\right]^{2}}{(p 1-p 2)^{2}}
$$

Trong đó: $\mathrm{n}_{1}$ : cỡ mẫu nhóm điều trị bằng MTA $\mathrm{n}_{2}$ : cỡ mẫu nhóm điều trị bằng Biodentine

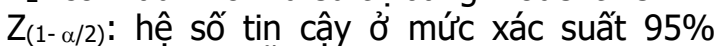
$(=1,96) ; Z_{1-\beta}:$ lực mẫu $(=80 \%)$

$\mathrm{p}_{1}$ : Kết quả hình thành cầu ngà trên thực nghiệm của Andiara De Rossi khi điêu trị tủy buồng bằng MTA là $72,2 \%$ [5] 
$\mathrm{p}_{2}$ : Kết quả hình thành cầu ngà trên thực nghiệm của Andiara De Rossi khi điều trị tủy buồng bằng Biodentine là $96,8 \%$ [5]

$\mathrm{p}=(\mathrm{p} 1+\mathrm{p} 2) / 2$. Theo công thức tính được cõ mẫu cần thiết tối thiểu cho mỗi nhóm nghiển cứu là $n=n_{1}=n_{2}=59$. Cụ thể chúng tôi đã can thiệp trên cỡ mẫu: $n=96$ răng cho mỗi nhóm. Qua theo dõi 3 đợt khám trong 9 tháng, cõ̃ mẫu nghiên cứu chúng tôi thu được:

- Ở nhóm can thiệp (nhóm sử dụng Biodentine): Khám sau 3 tháng: 87 rằng $(90,6 \%)$; Khám sau 6 tháng: 84 răng $(87,5 \%)$; Khám sau 9 tháng: 83 răng $(86,5 \%)$.

- Ở nhóm đối chứng (nhóm sử dụng MTA): Khám sau 3 tháng: 93 răng $(96,9 \%)$; Khám sau 6 tháng: 87 răng $(90,6 \%)$; Khám sau 9 tháng: 77 răng $(80,2 \%)$.

Tuy nhiên, so với cõ mẫu đã tính theo công thức, sau can thiệp cả nhóm can thiệp $(n=83)$ và nhóm đối chứng $(\mathrm{n}=77)$ đều có cõ mẫu lớn hơn cỡ mẫu tối thiểu cần có $(n=59)$. Vì vậy cõ mẫu trong nghiên cứu đảm bảo tính khoa học.

\subsubsection{Chọn mấu}

Mẫu nghiên cứu được lựa chọn theo các bước sau: - Khám và chẩn đoán bệnh lý tuỷ, những bệnh nhân từ 4-8 tuổi có ít nhất 01 răng hàm sữa sâu có chỉ định điều trị tủy buồng. Bệnh nhân và phụ huynh sẽ được mời làm thủ tục tham gia nghiên cứu, được một bản cung cấp thông tin về nghiên cứu can thiệp. Phụ huynh cần điền đầy đủ thông tin và ký vào bản cung cấp thông tin và đớn tình nguyện tham gia nghiên cứu.

- Răng có chỉ định lấy tuỷ buồng sẽ được lựa chọn ngẫu nhiên vào một trong hai nhóm sử dụng MTA (nhóm 1) hoặc Biodentine (nhóm 2)

2.4. Phân tích và xử lý số liệu. Số liệu được nhập bằng phần mềm Epi - Info 6.0 và xử lý bằng phần mềm thống kê SPSS 20.0. Sử dụng phân tích mô tả tần số, tỷ lệ với các biến nhị phân. Các thuật toán để kiểm định đối với các biến định tính và định lượng.

\section{KẾT QUẢ NGHIÊN CỨU}

Bảng 3.1. Triệu chứng cơ năng răng nghiên cứu theo dôi theo thời gian

\begin{tabular}{|c|c|c|c|c|c|c|c|}
\hline \multirow{2}{*}{\multicolumn{2}{|c|}{$\begin{array}{l}\text { Thời gian } \\
\text { Triệu chứng }\end{array}$}} & \multicolumn{2}{|c|}{ Sau 3 tháng } & \multicolumn{2}{|c|}{ Sau 6 tháng } & \multicolumn{2}{|c|}{ Sau 9 tháng } \\
\hline & & \multirow{2}{*}{$\begin{array}{c}\begin{array}{c}\text { MTA } \\
(\mathbf{n}=\mathbf{9 3})\end{array} \\
0(0,0) \\
\end{array}$} & \multirow{2}{*}{$\begin{array}{c}\begin{array}{c}\text { Biodentine } \\
(\mathbf{n}=\mathbf{8 7})\end{array} \\
0(0,0) \\
\end{array}$} & \multirow{2}{*}{$\begin{array}{c}\begin{array}{c}\text { MTA } \\
(\mathbf{n}=\mathbf{8 7})\end{array} \\
0(0,0)\end{array}$} & \multirow{2}{*}{$\begin{array}{c}\begin{array}{c}\text { Biodentine } \\
(\mathbf{n}=\mathbf{8 4})\end{array} \\
0(0,0) \\
\end{array}$} & \multirow{2}{*}{\begin{tabular}{|c|} 
MTA \\
$(\mathbf{n = 7 7 )})$ \\
$0(0,0)$ \\
\end{tabular}} & \multirow{2}{*}{$\begin{array}{c}\begin{array}{c}\text { Biodentine } \\
(\mathbf{n}=\mathbf{8 3})\end{array} \\
0(0,0) \\
\end{array}$} \\
\hline \multirow{2}{*}{$\begin{array}{l}\text { Răng đau } \\
\text { tự nhiên }\end{array}$} & $\mathrm{n}(\%)$ & & & & & & \\
\hline & $p\left(\chi^{2}\right)$ & & & & \multicolumn{2}{|r|}{-} \\
\hline \multirow{2}{*}{$\begin{array}{l}\text { Răng đau } \\
\text { khi ăn nhai }\end{array}$} & $n(\%)$ & $0(0,0)$ & $0(0,0)$ & $1(1,1)$ & $0(0,0)$ & $1(1,3)$ & $1(1,2)$ \\
\hline & $\mathrm{p}\left(\chi^{2}\right)$ & & & \multicolumn{2}{|r|}{0,05} \\
\hline \multirow{2}{*}{$\begin{array}{c}\text { Không } \\
\text { đau }\end{array}$} & $n(\%)$ & $93(100,0)$ & $87 \quad(100,0)$ & $86(98,9)$ & $84(100,0)$ & $76(98,7)$ & $82(98,8)$ \\
\hline & $\mathrm{p}\left(\chi^{2}\right)$ & \multicolumn{2}{|c|}{$>0,05$} & \multicolumn{2}{|c|}{$>0,05$} & \multicolumn{2}{|r|}{0,05} \\
\hline
\end{tabular}

Nhận xét: sau 3 tháng điều trị, các răng ở cả nhóm chứng (MTA) và nhóm can thiệp (Biodentine) đều không ghi nhận có các dấu hiệu cơ năng bệnh lý. Theo dõi sau 6 tháng, ở nhóm điều trị bằng MTA xuất hiện 1 răng $(1,1 \%)$ có dấu hiệu đau khi ăn nhai. Nhóm điều trị bằng Biodentine ghi nhận $100 \%$ các răng không đau. Sau điều trị 9 tháng, ở cả nhóm điều trị bằng MTA và Biodentine đều có 1 răng đau khi ăn nhai. Tuy nhiên, sự khác biệt giữa hai nhóm không có ý nghĩa thống kê với p>0,05.

Bảng 3.2. Triệu chứng thức thể răng nghiên cứu theo dối theo thời gian

\begin{tabular}{|c|c|c|c|c|c|c|c|}
\hline \multirow{2}{*}{\multicolumn{2}{|c|}{ Triệu chứng }} & \multicolumn{2}{|c|}{ Sau 3 tháng } & \multicolumn{2}{|c|}{ Sau 6 tháng } & \multicolumn{2}{|c|}{ Sau 9 tháng } \\
\hline & & \multirow{2}{*}{$\begin{array}{c}\begin{array}{c}\text { MTA } \\
(\mathbf{n}=93)\end{array} \\
0(0,0) \\
\end{array}$} & \multirow{2}{*}{$\begin{array}{c}\text { Biodentine } \\
(\mathbf{n = 8 7})\end{array}$} & \multirow{2}{*}{$\begin{array}{c}\begin{array}{c}\text { MTA } \\
(\mathbf{n}=\mathbf{8 7})\end{array} \\
1(1,1)\end{array}$} & \multirow{2}{*}{$\begin{array}{c}\begin{array}{c}\text { Biodentine } \\
(\mathbf{n}=\mathbf{8 4})\end{array} \\
0(0,0) \\
\end{array}$} & \multirow{2}{*}{$\begin{array}{c}\begin{array}{c}\text { MTA } \\
(\mathbf{n = 7 7})\end{array} \\
1(1,3)\end{array}$} & \multirow{2}{*}{\begin{tabular}{|c|}
$\begin{array}{c}\text { Biodentine } \\
(\mathbf{n}=\mathbf{8 3})\end{array}$ \\
$1(1,2)$ \\
\end{tabular}} \\
\hline \multirow{2}{*}{$\begin{array}{l}\text { Răng lung } \\
\text { lay bệnh lý }\end{array}$} & n (\%) & & & & & & \\
\hline & $\mathrm{p}\left(\chi^{2}\right)$ & \multicolumn{2}{|r|}{-} & \multicolumn{2}{|r|}{-} & \multicolumn{2}{|r|}{0,05} \\
\hline \multirow{2}{*}{$\begin{array}{c}\text { Lợi sưng } \\
\text { nề, đỏ }\end{array}$} & $n(\%)$ & $0(0,0)$ & $0(0,0)$ & $0(0,0)$ & $0(0,0)$ & $0(0,0)$ & $0(0,0)$ \\
\hline & $\mathrm{p}\left(\chi^{2}\right)$ & \multicolumn{2}{|l|}{2.} & \multicolumn{2}{|r|}{-} & \multicolumn{2}{|r|}{-} \\
\hline \multirow{2}{*}{$\begin{array}{c}\text { Có áp xe } \\
\text { lợi }\end{array}$} & $n(\%)$ & $0(0,0)$ & $0(0,0)$ & $0(0,0)$ & $0(0,0)$ & $1(1,3)$ & $0(0,0)$ \\
\hline & $\mathrm{p}\left(\chi^{2}\right)$ & \multicolumn{2}{|r|}{ 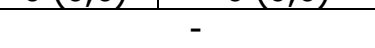 } & \multicolumn{2}{|l|}{, } & \multicolumn{2}{|r|}{ (2) } \\
\hline \multirow{2}{*}{$\begin{array}{c}\text { Có lố rò, sẹo } \\
\text { rò ở lợi }\end{array}$} & $n(\%)$ & $0(0,0)$ & $0(0,0)$ & $1(1,1)$ & $0(0,0)$ & $0(0,0)$ & $0(0,0)$ \\
\hline & $p\left(\chi^{2}\right)$ & \multicolumn{2}{|r|}{-} & \multicolumn{2}{|r|}{-} & \multicolumn{2}{|r|}{ 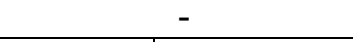 } \\
\hline \multirow{2}{*}{$\begin{array}{l}\text { Có lõm do } \\
\text { tiêu xương }\end{array}$} & $n(\%)$ & $0(0,0)$ & $0(0,0)$ & $0(0,0)$ & $0(0,0)$ & $0(0,0)$ & $0(0,0)$ \\
\hline & $\mathrm{p}\left(\chi^{2}\right)$ & \multicolumn{2}{|r|}{ - } & & \\
\hline
\end{tabular}

Nhận xét: sau 3 tháng điều trị, khám ở cả nhóm chứng (MTA) và nhóm can thiệp (Biodentine) các răng đều không ghi nhận có triệu chứng thực thể bệnh lý trên lâm sàng. Theo dõi sau 6 tháng, ở 
nhóm điều trị bằng MTA xuất hiện 1 răng $(1,1 \%)$ có dấu hiệu lung lay bệnh lý và có lỗ dò ở lợi. Nhóm điều trị bằng Biodentine không ghi nhận các dấu hiệu lâm sàng bệnh lý. Sau điều trị 9 tháng, ở nhóm điều trị MTA có 1 răng $(1,3 \%)$ lung lay bệnh lý và có áp xe lợi ở mă̆t ngoài, nhóm Biodentine có 1 răng $(1,2 \%)$ lung lay bệnh lý. Tuy nhiên, sự khác biệt không có ý nghĩ̃a thống kê với p>0,05.

Bảng 3.3. Triệu chứng Xquang của răng nghiên cứu theo dối theo thời gian

\begin{tabular}{|c|c|c|c|c|c|c|c|}
\hline \multirow{2}{*}{\multicolumn{2}{|c|}{ Triệu chứng }} & \multicolumn{2}{|c|}{ Sau 3 tháng } & \multicolumn{2}{|c|}{ Sau 6 tháng } & \multicolumn{2}{|c|}{ Sau 9 tháng } \\
\hline & & \multirow{2}{*}{ 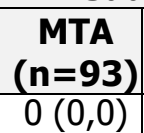 } & \multirow{2}{*}{$\begin{array}{c}\text { Biodentine } \\
(\mathbf{n}=\mathbf{8 7}) \\
0(0,0)\end{array}$} & \multirow{2}{*}{\begin{tabular}{|c|}
$\begin{array}{c}\text { MTA } \\
(\mathbf{n}=\mathbf{8 7})\end{array}$ \\
$1(1,1)$ \\
\end{tabular}} & \multirow{2}{*}{$\begin{array}{c}\begin{array}{c}\text { Biodentine } \\
(\mathbf{n}=\mathbf{8 4})\end{array} \\
0(0,0)\end{array}$} & \multirow{2}{*}{$\begin{array}{c}\text { MTA } \\
(\mathbf{n}=77) \\
2(2,6)\end{array}$} & \multirow{2}{*}{$\begin{array}{c}\begin{array}{c}\text { Biodentine } \\
(\mathbf{n}=\mathbf{8 3})\end{array} \\
1(1,2)\end{array}$} \\
\hline & $n(\%)$ & & & & & & \\
\hline chằng & $\mathrm{p}\left(\chi^{2}\right)$ & & & \multicolumn{2}{|c|}{$>0,05$} \\
\hline \multirow{2}{*}{$\begin{array}{l}\text { Xuất hiện nội tiêu } \\
\text { hoặc ngoại tiêu }\end{array}$} & $\mathrm{n}(\%)$ & $0(0,0)$ & $0(0,0)$ & $3(3,4)$ & $1(1,2)$ & $2(2,6)$ & $1(1,2)$ \\
\hline & $\mathrm{p}\left(\chi^{2}\right)$ & \multicolumn{2}{|r|}{-} & \multicolumn{2}{|c|}{$>0,05$} & \multicolumn{2}{|c|}{$>0,05$} \\
\hline \multirow{2}{*}{$\begin{array}{l}\text { Thấu quaang vùng } \\
\text { chẽ chân răng }\end{array}$} & $\mathrm{n}(\%)$ & $0(0,0)$ & $0(0,0)$ & $1(1,1)$ & & $1(1,3)$ & $1(1,2)$ \\
\hline & $\mathrm{p}\left(\chi^{2}\right)$ & & & \multicolumn{2}{|c|}{$>0,05$} \\
\hline
\end{tabular}

Nhận xét: Theo dõi sau 3 tháng điêu tri, ở MTA có 3 răng (3,9\%) ghi nhận dấu hiêu bênh lý cả nhóm chứng (MTA) và nhóm can thiệp trong đó có 1 răng có dãn rộng dây chằng quanh (Biodentine) đều không ghi nhận các dấu hiệu răng, 1 răng có dãn rộng dây chằng quanh răng bênh lý trên phim Xquang. Sau 6 tháng, nhóm kết hợp với ngoại tiêu và thấu quang vùng chẽ, 1 điều trị bằng MTA ghi nhận 3 răng $(3,4 \%)$ có răng có xuất hiện nội tiêu; ở nhóm Biodentine dấu hiệu bệnh lý bao gồm: 1 răng có dãn rộng ghi nhận 2 răng bệnh lý $(2,4 \%)$ gồm 1 răng có dây chẳng quanh răng, thấu quang vùng chẽ và dãn rộng dây chẳng quanh răng và nội tiêu, 1 ngoại tiêu; 2 răng xuất hiện nội tiêu. Ở nhóm răng có thấu quang vùng chẽ. Tuy nhiên, sự Biodentine chỉ có 1 răng ghi nhận có dấu hiệu khác biệt giữa hai nhóm theo thời gian không có nội tiêu (1,2\%). Sau 9 tháng theo dõi, nhóm ý nghĩa thống kê với p>0,05.

Bảng 3.4. Kêt quả điều trị tủy buồng bằng MTA và Biodentine

\begin{tabular}{|c|c|c|c|c|}
\hline & & MTA & Biodentine & $\mathbf{p}$ \\
\hline & & $n=96$ & $n=96$ & \\
\hline 3 the & dõi & $n=93$ & $n=87$ & \\
\hline lâm càng & Thành công & $93(100 \%)$ & $87(100 \%)$ & - \\
\hline Lam sang & Thất bai & $0(0,0 \%)$ & $0(0,0 \%)$ & - \\
\hline & Thành cồng & $93(100 \%)$ & $87(100 \%)$ & - \\
\hline Xquang & Thất bại & $0(0,0 \%)$ & $0(0,0 \%)$ & - \\
\hline 6 the & dõi & $n=87$ & $n=84$ & \\
\hline I f̂m cìng & Thành công & $86(98,9 \%)$ & $84(100 \%)$ & \\
\hline Lam sang & Thất bai & $1(1,1 \%)$ & $0(0,0 \%)$ & - \\
\hline & Thành cồng & $84(96,6 \%)$ & $83(98,8 \%)$ & \\
\hline xquang & Thất bại & $3(3,4 \%)$ & $1(1,2 \%)$ & $>0,05$ \\
\hline 9 thá & dõi & $n=77$ & $n=83$ & \\
\hline l âm sàng & Thành công & $76(98,7 \%)$ & $82(98,8 \%)$ & $>005$ \\
\hline Lam sang & Thất bai & $1(1,3 \%)$ & $1(1,2 \%)$ & $>0,05$ \\
\hline Xauana & Thành cống & $74(96,1 \%)$ & $81(97,6 \%)$ & $>0,05$ \\
\hline & Thất bại & $3(3,9 \%)$ & $2(2,4 \%)$ & \\
\hline
\end{tabular}

Nhận xét: Sau 3 tháng điều trị, cả hai nhóm đều có tỷ lệ thành công là $100 \%$ đánh giá cả trên lâm sàng và Xquang. Sau 6 tháng, đánh giá trên lâm sàng và Xquang nhóm điều trị bằng Biodentine đều có tỷ lệ thành công cao hơn nhóm điều trị bằng MTA ( $100 \%$ và $98,8 \%$ so với $98,9 \%$ và $96,6 \%$ ) và tỷ lệ thành công trên lâm sàng đều cao hơn trên Xquang. Sau 9 tháng điều trị, cả hai nhóm đều có tỷ lệ thành công trên lâm sàng tương đương nhau. Trên Xquang nhóm điều trị bằng Biodentine có tỷ lệ cao hơn nhóm điều trị bằng MTA (97,6\% so với 96,1\%). Tuy nhiên, sự khác biệt tỷ lệ thành công và thất bai trên lâm sàng và Xquang giữa hai nhóm ở các thời điểm không có ý nghĩa thống kê với p>0,05.

\section{BÀN LUÂ̂N}

Điều trị lấy tuỷ buồng là phương pháp điều trị phổ biến đối với những răng hàm sữa bi sâu sát buồng tuỷ hoăcc có những điểm hở tuỷ. Trong quá trình điều trị, tủy buồng răng sữa bị lấy bỏ và bề mặt mô tủy được xử lý bằng chất băng 
tủy. Với sự phát triển của các vật liệu, Mineral trioxide aggregate (MTA) là khoáng chất tổng hợp đã ra đời và được sử dụng phổ biến trong nha khoa vì khả năng kín khít rất tốt, tương hợp sinh học và kích thích hình thành mô cứng cao [6].

Từ các đặc tính sinh học của xi măng Portland đã dẫn đến sự phát triển của Biodentine. Ứng dụng của Biodentine trong một nghiên cứu in vitro trên răng hàm của con người qua chụp cắt lớp cho thấy độ dày cầu ngà răng do Biodentine tạo ra cao hơn so với MTA và các vật liệu khác [7].

Trong nghiên cứu này, để đánh giá hiệu quả của MTA và Biodentine chúng tôi sử dụng hai vật liệu này để đặt trong buồng tuỷ ở răng hàm sửa của trẻ từ 4-8 tuổi có chỉ định điều trị lấy tuỷ buồng, trong đó, MTA được coi là nhóm đối chứng.

Kết quả nghiên cứu chúng tôi nhận thấy thông thường một răng nếu có dấu hiệu thất bại trên lâm sàng, thường sẽ có dấu hiệu thất bại trên phim Xquang. Tuy nhiên, sự xuất hiện dấu hiệu thất bại trên phim Xquang chưa chắc đã có sự xuất hiệu dấu hiệu thất bại trên lâm sàng tương ứng. Cụ thể sau 3 tháng điều trị, 100\% các răng ở cả hai nhóm MTA và Biodentine không xuất hiện dấu hiệu thất bại cả trên lâm sàng và Xquang. Tuy nhiên sau 6 tháng, ở nhóm điều trị bằng MTA xuất hiện một răng đau khi ăn nhai, răng này cũng lung lay độ 3 và có một lỗ rò ở lợi. Nhóm điêu trị bằng Biodentine không có răng nào xuất hiện dấu hiệu bệnh lý trên lâm sàng. Trên phim Xquang nhóm điều trị bằng MTA ghi nhận 3 răng $(3,4 \%)$ có dấu hiệu bệnh lý bao gồm: 1 răng có dãn rộng dây chẳng quanh răng, thấu quang vùng chẽ và ngoại tiêu, răng này đã xuất hiện các dấu hiệu lâm sàng ở trên; 2 răng xuất hiện nội tiêu và không có các dấu hiệu lâm sàng như đã mô tả. ở nhóm điêu trị bằng Biodentine ghi nhận 1 răng có dấu hiệu nội tiêu $(1,2 \%)$ và cũng không xuất hiện các triệu chứng lâm sàng bệnh lý. Sau điêu trị 9 tháng, ở cả nhóm điêu trị bằng MTA và Biodentine đêu có 1 răng xuất hiện đau khi ăn nhai, các răng này cũng có dâu hiệu lung lay bệnh lý. Ngoài ra nhóm điều trị bằng MTA còn xuất hiện 1 răng có áp xe ở ngách lợi tương ứng. Trên phim Xquang, ở nhóm điều trị bằng MTA, răng có dấu hiệu đau có dãn rộng dây chẳng quanh răng, răng có áp xe ở ngách lợi có dãn rộng dây chằng quanh răng kết hợp với ngoại tiêu và thấu quang vùng chẽ, nhóm này cũng xuất hiện 1 răng có nội tiêu. Ở nhóm điêu trị bằng Biodentine, răng xuất hiện dấu hiệu đau có dãn rộng dây chằng quanh răng và nội tiêu, ngoài ra có 1 răng có thấu quang vùng chẽ (bảng 3.1, 3.2 và 3.3).

Tổng hợp đánh giá kết quả điều trị chung của hai vật liệu chúng tôi ghi nhận tỷ lệ thành công cao cả trên lâm sàng và Xquang, với MTA tỷ lệ thành công là $98,7 \%$ trên lâm sàng và $96,1 \%$ trên Xquang, còn với Biodentine là $98,8 \%$ và $97,6 \%$ sau 9 tháng điều trị (bảng 3.4). Kết quả này cũng tương tự kết quả của một số nghiên cứu trên thế giới. Nghiên cứu của Rajasekharan và cộng sự năm 2016 tại Bỉ trên trẻ từ $3-8$ tuổi cho tỷ lề thành công trên lâm sàng với với Biodentine ${ }^{\mathrm{TM}}$ là $96 \%$ và với MTA trắng là $100 \%$ sau 12 tháng [8]. Nasrallah H và cộng sự năm 2018 nghiên cứu điêu trị tuỷ buồng với Biodentine trên 75 răng hàm sữa, sau 12 tháng theo dõi cho tỷ lệ thành công trên lâm sàng là 98,7\% [9] tương tự như kết quả nghiên cứu của chúng tôi.

\section{KẾT LUẬN}

Đây là thử nghiệm lâm sàng ngẫu nhiên có nhóm chứng để đánh giá hiệu quả của Biodentine trong điều trị lấy tuỷ buồng răng hàm sữa ở trẻ. Sau 9 tháng theo dõi sau điêu trị, trên lâm sàng Biodentine và MTA có tỷ lệ thành công tương đương nhau $(98,8 \%$ và $98,7 \%)$ còn trên Xquang, Biodentine có tỷ lệ thành công cao hơn so với MTA $(97,6 \%$ và $96,1 \%)$. Như vậy các kết quả thu được khi sử dụng Biodentine để điều trị tuỷ buồng sau 9 tháng theo dõi là rất tốt; tuy nhiên, cần có các nghiên cứu sâu hơn với cỡ mẫu lớn hơn và thời gian theo dõi dài hơn để đánh giá toàn diện về vật liệu này.

\section{TÀI LIÊU THAM KHẢO}

1. American Academy of Pediatric Dentistry: Reference Manual. Guideline on Pulp Therapy for Primary and Immature Permanent Teeth. 2014;37(6): 244-252.

2. Eidelman E, Holan G, Fuks AB. Mineral trioxide aggregate vs formocresol in pulpotomized primary molars: a preliminary report. Pediatric Dentistry. 2001;23,15-18.

3. Torabinejad $\mathbf{M}$, Chivian $\mathbf{N}$. Clinical applications of mineral trioxide aggregate. Journal of Endodontics. 1999;25,197-205.

4. Marconyak Jr LJ, Kirkpatrick TC, Roberts HW et al. A comparison of coronal tooth discoloration elicited by various endodontic reparative material. J Endod. 2016;42(3):470-473.

5. Andiara De Rossi et al. Comparison of Pulpal Responses to Pulpotomy and Pulp Capping with Biodentine and Mineral Trioxide Aggregate in Dogs. J Endod. 2014;40(9):1362-1369.

6. Chen JW, Jorden $\mathbf{M}$. Materials for primary tooth pulp treat- ment: the present and the future. Endod Topics. 2010;23:41-49.

7. Nowicka A, Wilk G, Lipski M, Kołecki J, Buczkowska-Radlińska J. 'Tomographic evaluation of reparative dentin formation after 
direct pulp capping with $\mathrm{Ca}(\mathrm{OH}) 2$, MTA, biodentine, and dentin bonding system in human teeth. J Endod. 2015;41:1234-1240.

8. Rajasekharan S, Martens LC, Vandenbulcke J, et al (2016). Efficacy of three different pulpotomy agents in primary molars: a randomized control trial. Epub, 50, 3, 215-228.

9. Nasrallah H, El Noueiri B, Pilipili C, Ayoub F. Clinical and Radiographic Evaluations of Biodentine ${ }^{\mathrm{TM}}$ Pulpotomies in Mature Primary Molars (Stage 2). Int J Clin Pediatr Dent. 2018;11(6):496-504.

\section{ĐÁNH GIÁ SỰ THAY ĐỔI CÁC THÔNG SỐ Pa02/FiO2, SP02/FiO2 TRONG QUÁ TRÌNH ĐIỀU TRI VÀ KẾT QUẢ ĐIỀU TRI BÊNH NHÂN SUY HÔ HẤP TIẾN TRIỂN DO CÚM A TẠI BỆNH VIỆN BÊ̂NH NHIỆT ĐỚI TRUNG ƯO'NG (2019-2021)}

\section{TÓM TẮT}

Muc tiêu: mô tả được sự thay đổi các thông số $\mathrm{PaO} 2 / \mathrm{FiO} 2, \mathrm{SPO} 2 / \mathrm{FiO} 2$ trong quá trình điêu trị và kết quả điều trị bệnh nhân suy hô hấp tiến triển do cúm $A$ tai Bênh viên Bênh nhiêt đới Trung Ương (2019 2021). Đối tượng \& phương pháp: mô tả cắt ngang 30 bếnh nhân suy hô hấp tiến triển (ARDS) do cúm $A$. Kết quả: ở nhóm bệnh nhân sống sót chỉ số $\mathrm{PaO} 2 / \mathrm{FiO} 2$ tăng dần trong quá trình điều trị, mức tăng có ý nghĩa với $\mathrm{p}<0,05$. Nhóm bệnh nhân tử vong, ch số $\mathrm{PaO} 2 / \mathrm{FiO} 2$ có xu hướng không thay đổi trong quá trình điều trị, sự khác biệt không có ý nghĩa với $\mathrm{p}>$ 0,05 . Tỷ số $\mathrm{PaO} 2 / \mathrm{FiO} 2$ và $\mathrm{SPO} 2 / \mathrm{FiO} 2$ trước điều trị có liên quan với tỷ lệ tử vong. Diện tích dưới đường cong AUC của $\mathrm{PaO} 2 / \mathrm{FiO} 2$ là 0,625 , điểm cắt là 90 thì độ nhạy và độ đặc hiệu của tiên đoán tử vong lân lượt là $89 \%$ và $42 \%$. Diển tích dưới đường cong AUC của SPO2/FiO2 là 0,727, điểm cắt là 116 , độ nhạy và độ đặc hiệu của tiên đoán tử vong lần lượt là $89 \%$ và $58 \%$. Tỷ lệ tử vong chung trong nghiên cứu là $40 \%$.

Tư khóa: Hội chứng suy hô hấp cấp tiến triển (ARDS), cúm $A$.

\section{SUMMARY \\ DESCRIBE THE CHANGE OF PARAMETERS PAO2/FIO2, SPO2/FIO2 DURING TREATMENT AND TREATMENT RESULTS OF PATIENTS WITH ACUTE RESPIRATORY DISTRESS SYNDROMECAUSED (ARDS) CAUSED BY INFLUENZA A AT THE NATIONAL HOSPITAL OF TROPICAL DISEASES (2019 - 2021) \\ Objective: Describe the change of parameters} $\mathrm{PaO} 2 / \mathrm{FiO2}$, SPO2/FiO2 during treatment and treatment results of patients with Acute Respiratory Distress Syndromecaused (ARDS) caused by influenza $A$ at the National Hospital of Tropical Diseases (2019

* Đai hoc Y Hà Nôi

Chịu trách nhiệm chính: Trần Văn Giang

Email: giangminh08@gmail.com

Ngày nhân bài: 14.9.2021

Ngày phản biên khoa hoc: 12.11.2021

Ngày duyệt bài: 22.11.2021
Trần Văn Giang*, Trương Tư Thế Bảo*

- 2021). Materials and methodes: Cross-sectional description of 30 patients with Acute Respiratory Distress Syndromecaused (ARDS) caused by influenza A. Results: In the group of surviving patients, the $\mathrm{PaO} 2 / \mathrm{FiO} 2$ index gradually increased during treatment, the increase was significant with $p<0.05$. In the group of patients who died, the $\mathrm{PaO} 2 / \mathrm{FiO}_{2}$ index tended to remain unchanged during treatment, the difference was not significant with $\mathrm{p}>0.05$. Pretreatment $\mathrm{PaO} 2 / \mathrm{FiO} 2$ and $\mathrm{SPO} 2 / \mathrm{FiO} 2$ ratios are associated with mortality. The area under the curve (AUC) of $\mathrm{PaO} 2 / \mathrm{FiO} 2$ was 0.625 , the cut-off point was 90 , the sensitivity and specificity of mortality prediction were $89 \%$ and $42 \%$. The area under the curve (AUC) of $\mathrm{SPO} 2 / \mathrm{FiO} 2$ was 0.727 , the cut-off point was 116 , and the sensitivity and specificity of mortality prediction were $89 \%$ and $58 \%$. Overall mortality in the study was $40 \%$.

Keywords: Acute Respiratory Distress Syndromecaused (ARDS), Influenza A.

\section{I. ĐĂT VẤN ĐỀ}

Cúm là một bệnh truyền nhiễm cấp tính của đường hô hấp, do virus cúm gây ra. Bệnh có thể diễn biến từ nhẹ đến nguy kịch như viêm phổi, suy hô hấp cấp, suy đa tạng và tử vong. Người già, trẻ em, hoắc người có cơ địa đặc biêt như mắc bệnh mạn tính, béo phì, suy giảm miến dịch có nguy cơ tiến triển nặng cao hơn [1].

Hội chứng suy hô hấp cấp tiến triển (ARDS) là một hội chứng bệnh lý trong đó màng phế nang mao mạch của phổi bị tổn thương cấp tính do nhiều nguyên nhân khác nhau dẫn đến tình trạng suy hô hấp nặng không đáp ứng với thở oxy liều cao[2]. ARDS là biến chứng hay gặp và gây tử vong nhiều nhất ở bệnh nhân nhiễm cúm $A$.

Hằng năm, trên toàn cầu, có hơn 10 triệu người phải nhập viện do cúm, gây ra 100.000 200.000 ca từ vong [3]. Tỷ lê chung của ARDS khoảng 150 trên 100000 ca bệnh, chiếm 10 $15 \%$ số bệnh nhân điều trị tại các đơn vị hồi sức. Tỷ lệ tử vong tại viện trung bình là $24 \%$ và tỷ lệ 